\title{
LncRNA MIR31HG Drives Oncogenicity by Inhibiting the Limb-Bud and Heart Development Gene ( $L B H)$ during Oral Carcinoma
}

\author{
Kuo-Wei Chang ${ }^{1,2,3}$, Wan-Wen Hung ${ }^{2}$, Chung-Hsien Chou ${ }^{2}$, Hsi-Feng Tu ${ }^{1,2,4}$, Shi-Rou Chang ${ }^{2}$, Ying-Chieh Liu ${ }^{2}$, \\ Chung-Ji Liu 1,5 (D) and Shu-Chun Lin $1,2,3, *$ (D)
}

\section{check for}

updates

Citation: Chang, K.-W.; Hung, W.-W.; Chou, C.-H.; Tu, H.-F.; Chang, S.-R.; Liu, Y.-C.; Liu, C.-J.; Lin, S.-C. LncRNA MIR31HG Drives Oncogenicity by Inhibiting the Limb-Bud and Heart Development Gene $(L B H)$ during Oral Carcinoma. Int. J. Mol. Sci. 2021, 22, 8383. https://doi.org/10.3390/ ijms 22168383

Academic Editor: Eric Parkinson

Received: 16 July 2021

Accepted: 3 August 2021

Published: 4 August 2021

Publisher's Note: MDPI stays neutral with regard to jurisdictional claims in published maps and institutional affiliations.

Copyright: (c) 2021 by the authors. Licensee MDPI, Basel, Switzerland. This article is an open access article distributed under the terms and conditions of the Creative Commons Attribution (CC BY) license (https:// creativecommons.org/licenses/by/ $4.0 /)$
1 Department of Dentistry, College of Dentistry, National Yang Ming Chiao Tung University, Taipei 112, Taiwan; ckcw@nycu.edu.tw (K.-W.C.); hsifeng@gmail.com (H.-F.T.); cjliu3229@gmail.com (C.-J.L.)

2 Institute of Oral Biology, College of Dentistry, National Yang Ming Chiao Tung University, Taipei 112, Taiwan; vivian25wen@gmail.com (W.-W.H.); michaelchou0806@gmail.com (C.-H.C.); s4103052122@gmail.com (S.-R.C.); yingchieh12@gmail.com (Y.-C.L.)

3 Department of Stomatology, Taipei Veterans General Hospital, Taipei 112, Taiwan

4 Department of Dentistry, National Yang Ming Chiao Tung Hospital, Yilan 260, Taiwan

5 Department of Dentistry, Taipei MacKay Memorial Hospital, Taipei 104, Taiwan

* Correspondence: shuchun@nycu.edu.tw; Fax: +886-2-2826-4053

\begin{abstract}
The miR-31 host gene (MIR31HG) encodes a long non-coding RNA (LncRNA) that harbors miR-31 in its intron 2; miR-31 promotes malignant neoplastic progression. Overexpression of MIR31HG and of miR-31 occurs during oral squamous cell carcinoma (OSCC). However, the downstream effectors modulated by MIR31HG during OSCC pathogenesis remain unclear. The present study identifies up-regulation of MIR31HG expression during the potentially premalignant disorder stage of oral carcinogenesis. The potential of MIR31HG to enhance oncogenicity and to activate Wnt and FAK was identified when there was exogenous MIR31HG expression in OSCC cells. Furthermore, OSCC cell subclones with MIR31HG deleted were established using a Crispr/Cas9 strategy. RNA sequencing data obtained from cells expressing MIR31HG, cells with MIR31HG deleted and cells with miR-31 deleted identified 17 candidate genes that seem to be modulated by MIR31HG in OSCC cells. A TCGA database algorithm pinpointed MMP1, BMP2 and Limb-Bud and Heart development $(L B H)$ as effector genes controlled by MIR31HG during OSCC. Exogenous $L B H$ expression decreases tumor cell invasiveness, while knockdown of $L B H$ reverses the oncogenic suppression present in MIR31HG deletion subclones. The study provides novel insights demonstrating the contribution of the MIR31HG-LBH cascade to oral carcinogenesis.
\end{abstract}

Keywords: carcinoma; LBH; MIR31HG; oral; precancer

\section{Introduction}

Head and neck squamous cell carcinoma (HNSCC), which includes oral SCC (OSCC), is one of the major causes of cancer death worldwide [1-3]. The survival rate of HNSCC has not been remarkably improved over past decades due mainly to our limited mechanistic understanding of relapse, drug resistance and metastasis [4,5]. To prevent progression from oral potentially malignant disorder (OPMD) to a full neoplasm is also likely way to improve the survival rate of individuals at risk [6,7]. Long non-coding RNAs (LncRNAs) and miRNAs are non-coding RNAs that are crucial to the regulation of pathogenesis, including the neoplastic process of HNSCC [8]. Our series of studies have identified the oncogenic roles that $m i R-31$ plays in OSCC by targeting suppressor molecules; these molecules control the induction of hypoxia, the induction of stemness, the creation of metabolic aberrances, and an increase in susceptibility to DNA damage [1,9-11]. The up-regulation of miR-31 occurs early during the OPMD stage, and this aberrance is a prognostic predictor of this disorder [12,13]. In addition, $m i R-31$ has been validated as 
an OSCC marker in biofluids, including plasma and saliva [14,15]. A further elucidation of the effectors or co-players associated with miR-31 should help to bring about further therapeutic advances.

It is known that LncRNAs play a range of versatile roles in physiological modulation [8]. In the nucleus, LncRNAs seem to be involved in reshaping the configuration of chromatin, guiding transcription factors to allow promoter activation, and acting as an isolator during inhibition of gene transcription [16]. In the cytosol, LncRNAs may interact with various molecules that modulate gene translation, as well as being able to complex with miRNA, which allows them to act as a sponge resulting in functional abrogation. MIR31HG, which localized on chromosome 9p21 and was previously defined LOC554202 locus, is a $\sim 150-\mathrm{Kb}$ gene that consists of 4 exons; it hosts miR-31 in its intron 2 [16-20]. MIR31HG is transcribed as a 2148-bp LncRNA, and this molecule has been shown to play diverse roles in various malignancies [19,21-31]. As a competing endogenous RNA, MIR31HG binds with multiple miRNAs and this activity acts as a sink that can either enrich or repress malignancy $[22,23,26,32,33]$. In non-small cell lung cancer (NSCLC), an up-regulated MIR31HG activates the EGFR/AKT cascade resulting in resistance to Gefitinib [34]. MIR31HG also activates the Wnt/ $\beta$-catenin cascades, which increases the aggressiveness of tumors [35]. Nuclear MIR31HG interacts with p16 to recruit polycomb proteins and this brings about p16 repression [18]. On the other hand, cytosolic MIR31HG interacts with YBX1 and this modulates the secretory phenotype [17]. In OSCC, miR-31 induces hypoxia by inhibiting FIH, which then activates HIF1 $\alpha$ [1]. Interestingly, MIR31HG acts together with miR-31 to complex with HIF1 $\alpha$ this then enriches the binding of HIF1 $\alpha /$ p300 to hypoxia response elements [19]. MIR31HG also targets p21 in HNSCC, which promotes the cell cycle and inhibits apoptosis [36]. However, by way of contrast, MIR31HG has been found to acts as a proapoptotic factor by down-regulating malignancies via the hypermethylation of various promotors [37]. The functional roles and specific downstream effectors of MIR31HG during OSCC remain to be clarified.

Limb-Bud and Heart development $(L B H)$ is a highly conserved transcriptional component originally found to regulate tissue development during early embryogenesis [38]. The Wnt-LBH regulatory axis is crucial for the maintenance of the basal lineage of mammary stem cells and the pathogenesis of the aggressive basal subtype of breast cancer $[39,40]$. In addition to the above, LBH also modulates Wnt-associated proliferation, apoptosis and tumorigenicity during breast carcinogenesis [41]. Furthermore, $L B H$ functions as suppressor during nasopharyngeal carcinoma, prostate carcinoma and NSCLC [42-45]. The roles played by LBH in OSCC pathogenesis remain hitherto obscure. MMP1 and BMP2 are known to modulate cell activity and the tumor microenvironment, as well as being factors associated with OSCC relapse $[5,46,47]$. This study identifies the up-regulation of MIR31HG in cytobrushed OPMD samples. Using knockout and expression strategies, followed by bioinformatic analysis and functional validation, this study shows that MIR31HG modulates MMP1, BMP2, and LBH expression to augment OSCC oncogenicity.

\section{Results}

\subsection{Up-Regulation of MIR31HG in OPMD and OSCC}

An analysis of the brushed samples showed an increase in MIR31HG expression for OPMD relative to that of the controls (Figure 1A; Table S1). ROC analysis revealed an accuracy of 0.76 when MIR31HG expression was used to separate OPMD samples from the control samples (Figure 1B). MIR31HG expression was not associated with the dysplasia state among the OPMD samples. The importance of MIR31HG to HNSCC was further specified using The Cancer Genome Atlas (TCGA) dataset, which confirmed MIR31HG up-regulation in tumors (Figure 1C). In addition, tumors that had MIR31HG expression levels within the highest quadrant had a worse survival than those that had MIR31HG expression levels within the lowest quadrant (Figure 1D). 
A

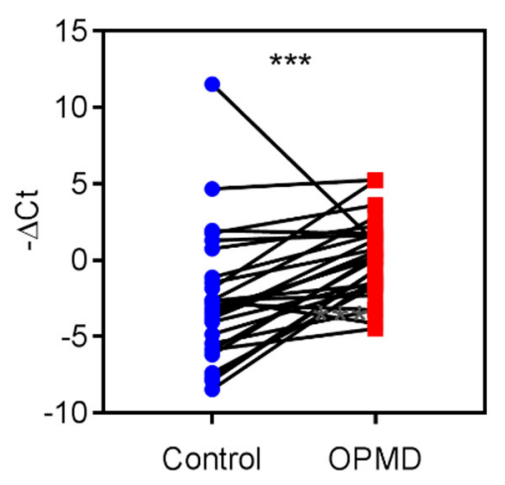

C

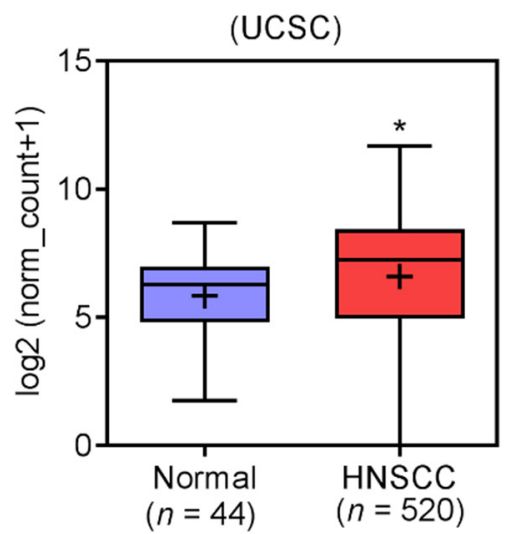

B

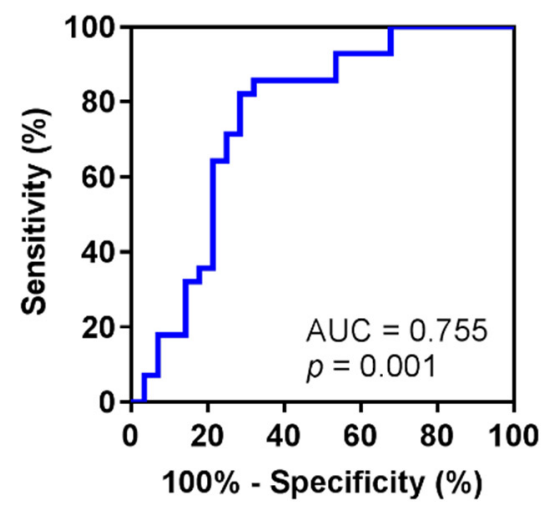

D

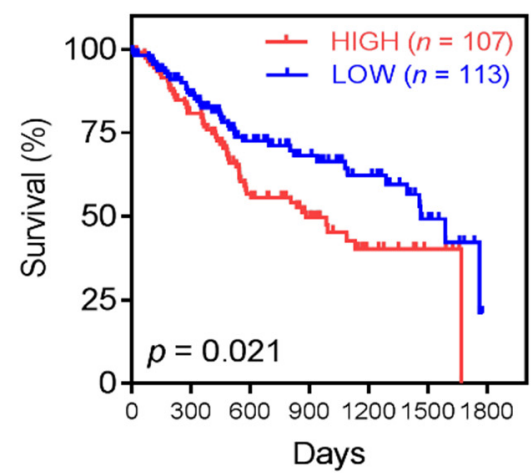

Figure 1. MIR31HG expression in brushed OPMD samples and the HNSCC dataset. (A) Beforeafter-blot demonstrating the increase in the $-\triangle \mathrm{Ct}$ values for MIR31HG obtained from samples of normal mucosa compared to those obtained from OPMD. (B) ROC curve of the $-\triangle \mathrm{Ct}$ of MIR31HG showing an accuracy of 0.76 when separating OPMD samples from control samples. (C) Increased MIR31HG expression in HNSCC tumors relative to normal tissues extracted from the TCGA dataset. (D) Kaplan-Meier survival analysis. This indicates that HNSCCs showing increased MIR31HG expression in the highest quadrant exhibits a worse prognosis than those with lower expression in the lowest quadrant. ${ }^{*}, p<0.05 ;{ }^{* * *}, p<0.001$.

\subsection{Overexpression of MIR31HG Enhances Various Oncogenic Phenotypes}

SAS cell line was successfully infected with lentivirus, and this resulted in overexpression of MIR31HG and GFP and this stable cell was designated OE, relative to the vector alone (VA) control (Table S2; Figure S1). A robust increase in MIR31HG expression was detected in the OE (Figure 2A). Proliferation rate, wound closure rate and cisplatin resistance increased in the $\mathrm{OE}$ (Figure 2B). Nevertheless, no change in sensitivity was found between OE and VA when other drugs were tested (Figure S2). Invasion and colony formation of the OE increased to different extents (Figure 2C). Thus, OE cell seemed to exhibit an increased trend towards tumorigenesis compared to VA cell (Figure 2D). 
A

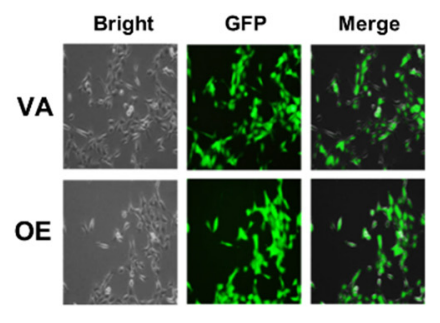

B

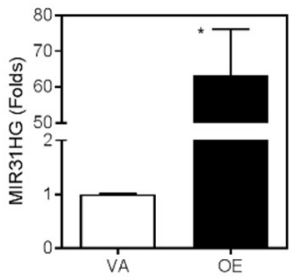

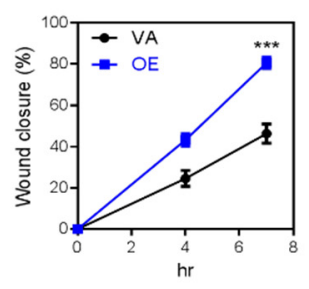

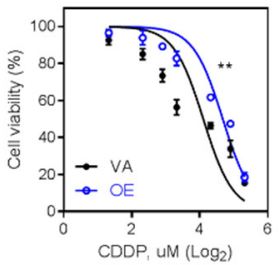

C
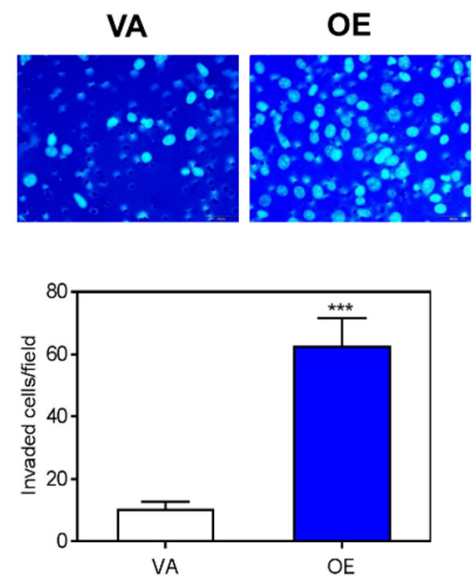

VA
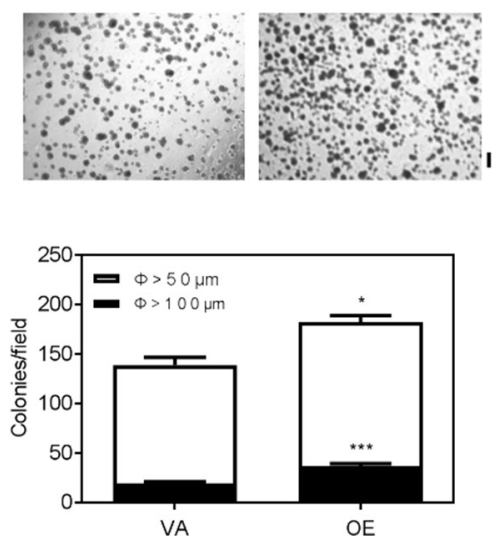

D
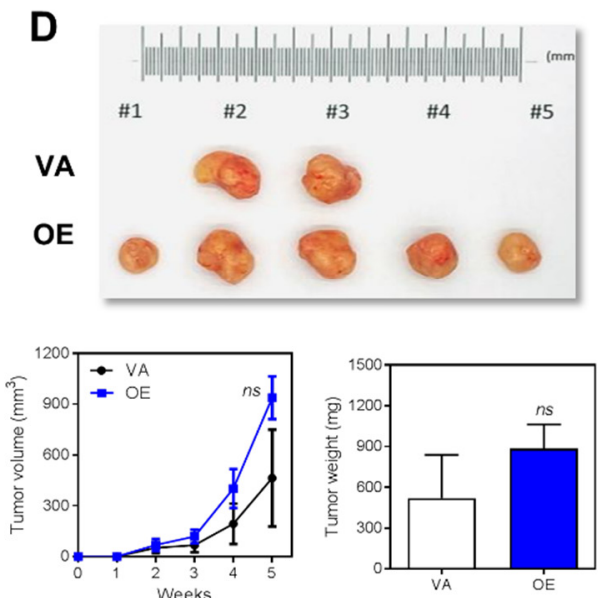

Figure 2. Exogenous MIR31HG overexpression increases the oncogenicity of SAS cells. (A) Left, stable cells with exogenous MIR31HG overexpression and control cells both exhibit green fluorescence indicating the presence of plasmid. Right, qRTPCR analysis shows that there is increased MIR31HG expression in OE cells. (B) OE cells exhibit an increased proliferation (Left), increased wound closure rate (Middle) and higher cisplatin resistance (Right) relative to VA cells. (C) OE cells exhibit increased invasion (Upper Left) and higher colony formation ability (Upper Right) relative to VA cells. The lower panels show the calculation. Bar, $200 \mu \mathrm{M}$. (D) Subcutaneous tumorigenesis assay. Left, resected tumors from the sacrificed animals. Middle, the growth rate of the tumors over a 5-week period. Right, the weight of the resected tumors. VA, vector alone. OE, stable MIR31HG overexpression. *,$p<0.05 ; * *, p<0.01 ; * *, p<0.001$.

\subsection{Overexpression of MIR31HG Activates the Wnt Pathway}

To pinpoint the influence of MIR31HG on various signals, a smaller plasmid was constructed that was able to transiently transfect cells (Figure S3; Table S2). SAS cells were transiently transfected to overexpress MIR31HG. The MIR31HG cells and control vector cells were designated $\mathrm{OE}$ and VA, respectively. Western blot analysis at $8 \mathrm{~h}$ after transfection showed increased expression of FAK/p-FAK, active $\beta$-catenin and TCF4, as well as decreased expression of $\mathrm{p}-\mathrm{GSK} 3 \beta$ expression (Figure 3A,B). Over the time course studied activation of AKT, ERK or src was not prominent (Figure 3B).

\subsection{Deletion of MIR31HG Reduces Oncogenic Phenotypes}

SAS cell subclones were established after transfecting cells with the appropriate plasmids followed by selection. PCR analysis revealed that there was homozygous deletion of MIR31HG in the KO4, KO15 and KO17 subclones (Figure S4). Sequencing confirmed that the deletions in the subclones spanned exon 1 to exon 4 of MIR31HG. qRT-PCR analysis confirmed a drastic decrease in both MIR31HG and miR-31 expression in the three subclones (Figure $4 \mathrm{~A}$, upper left). The deletions were associated with decreased proliferation, decreased migration and reduced colony formation (Figure 4A). The tumorigenic effect of the $\mathrm{KO} 4$ subclone were markedly decreased compared with that of the parental SAS cells (Figure 4B). When subclones KO4 and KO15 underwent exogenous overexpression of MIR31HG, this increased both the wound closure rate and invasion (Figure 4C). In addition, 
it was found the decreased colony formation capability of $\mathrm{KO} 4$ and $\mathrm{KO} 15$ was rescued by transient MIR31HG overexpression (Figure 4D).

A

\section{A}

FAK
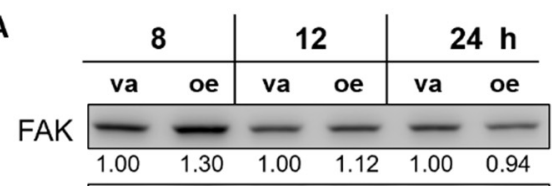

p-FAK

AKT
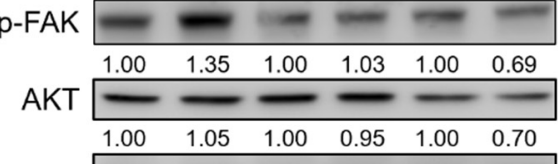

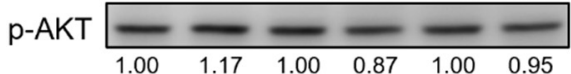

ERK
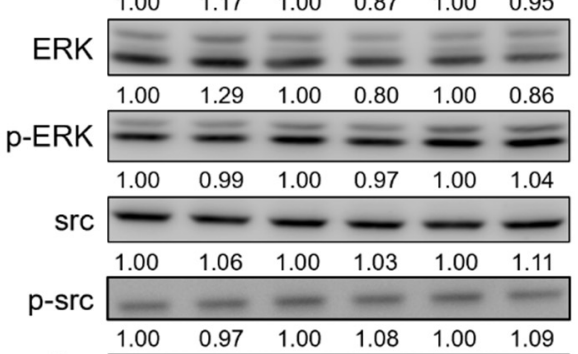

active

$\beta$-catenin

$\begin{array}{llllll}1.00 & 0.97 & 1.00 & 1.08 & 1.00 & 1.09\end{array}$

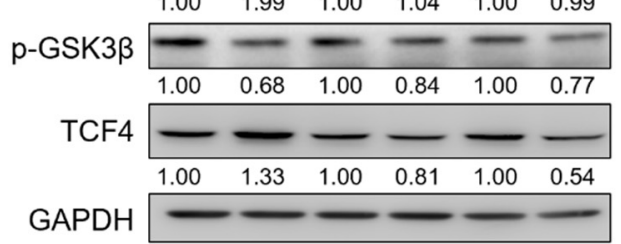

B
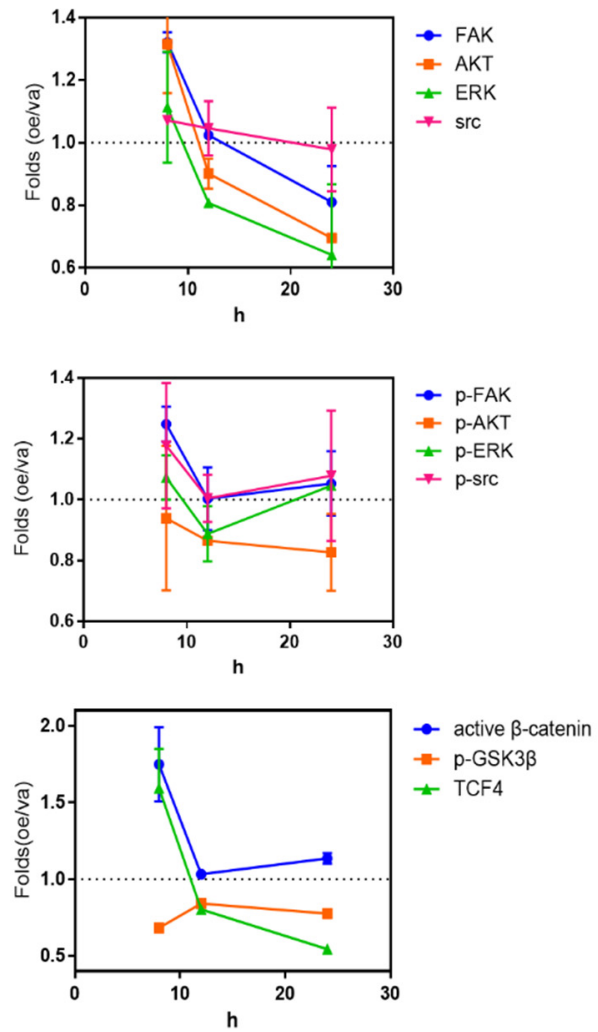

Figure 3. Signal activation after transient MIR31HG expression in SAS cells. (A) A representative Western blot analysis showing the expression of various signal factors after transient transfection with the MIR31HG plasmid for 8, 12, and $24 \mathrm{~h}$. The numbers are normalized values. (B) The changes of signal protein levels over the time course following transfection. Upper, FAK, AKT, ERK, and src; Middle, p-FAK, p-AKT, p-ERK, and p-src; Lower, active $\beta$-catenin, p-GSK3 $\beta$ and TCF4. va, vector alone; oe, transient MIR31HG overexpression.

\subsection{Identification of Downstream Effectors of MIR31HG}

To pinpoint the downstream effectors specific for MIR31HG, this study also established a miR-31 knockout cell subclone (designated $m i R-31 \mathrm{KO}$ ) from SAS cells. RNASeq was carried out on $\mathrm{OE}, \mathrm{KO} 4$, and miR-31KO cells. A total of 1436 transcripts were present in both the $\mathrm{OE}$ and $\mathrm{KO}$ sequencing datasets, but not present in the miR-31KO dataset; these were considered potential MIR31HG specific effectors (Figure 5A, Left). Among these, 102 positive effectors and 108 negative effectors were identified. Using an FPKM of more than 0.05 as the screening threshold, 22 positive transcripts and 19 negative transcripts were ultimately identified to be good candidates for MIR31HG specific effectors (Figure 5A, Middle; Table S3). After excluding pseudogenes, non-coding RNAs and various uncertain transcripts, 17 protein coding transcripts were finally retrieved as candidate effectors of MIR31HG in SAS cells (Figure 5A, Middle; Table S4). MMP1, BMP2, SLC2A13, and $\mathrm{LBH}$, all of which exhibited conspicuous changes in expression level, were further tested (Figure 5A, Right). A positive correlation between MIR31HG expression and the expression of MMP1 and BMP2; and a negative correlation between MIR31HG expression and SLC2A13 expression were identified in HNSCC samples using the TCGA dataset (Figure 5B; Figure S5). MMP1, BMP2 and SCL2A13 were up-regulated in OE cells and down-regulated in the $\mathrm{KO} 4$ cell subclone (Figure 5C, Left). In VA, MMP1, BMP2, and $S C L 2 A 13$ expression was slightly reduced by the knockdown of MIR31HG. However, in 
OE cells, up-regulated MMP1, BMP2 and SCL2A13 expression was more conspicuously decreased by the knockdown of MIR31HG (Figure 5C, Right). In the GSE37991 OSCC database, MMP1 and BMP2 expression was also up-regulated in tumors. The SCL2A13 study was terminated due to the discrepancies in tissues and cells. In OSCC cell lines, a positive correlation between MIR31HG expression and the expression of MMP1 was noted (Figure 5D). Western blot analysis revealed an increased MMP1 and BMP2 protein expression in OE cells, and a slight decrease in MMP1 and BMP2 protein expression in $\mathrm{KO} 4$ and $\mathrm{KO} 15$ cells (Figure 5E). The phenotypic impacts of MMP1 were further analyzed using knockdown of expression. The knockdown of $M M P 1$ did not alter the expression of MIR31HG, or did it affect the proliferation/migration of SAS cells (Figure S6A-C). Nonetheless it did reduce invasion and colony formation by SAS cells (Figure S6D,E). HNSCC in the TCGA dataset that had the highest levels of MMP1 expression also exhibited a trend to having a worse prognosis compared to the contrasting quadrant (Figure S6F).

A
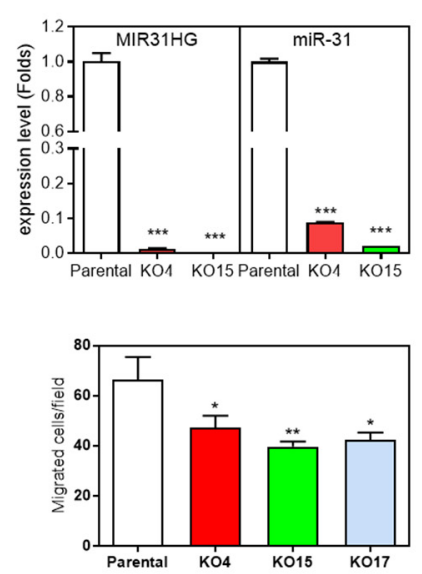

C

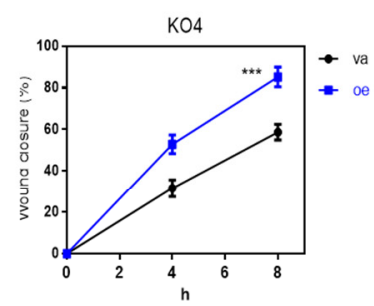

$\mathrm{KO} 4$

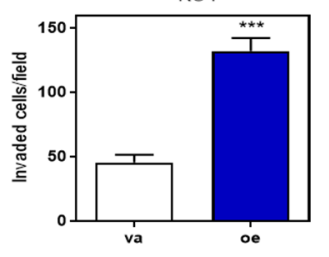

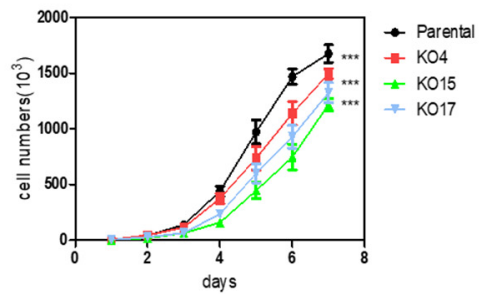
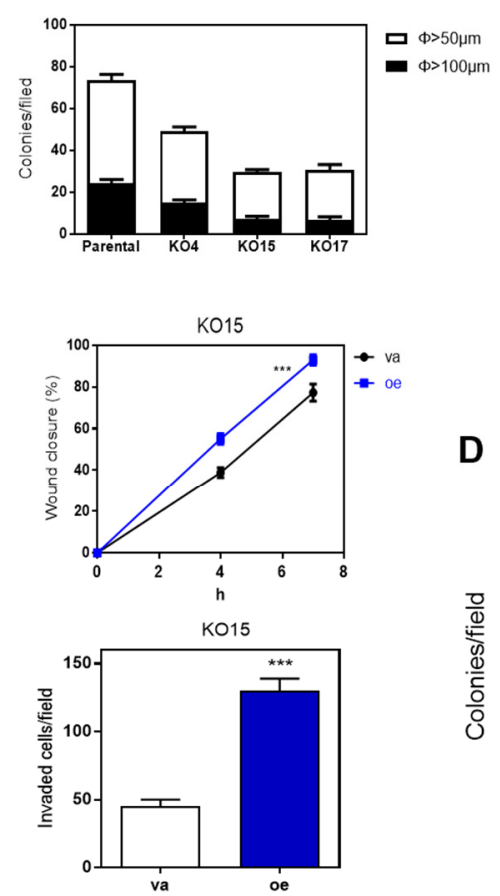

D
B
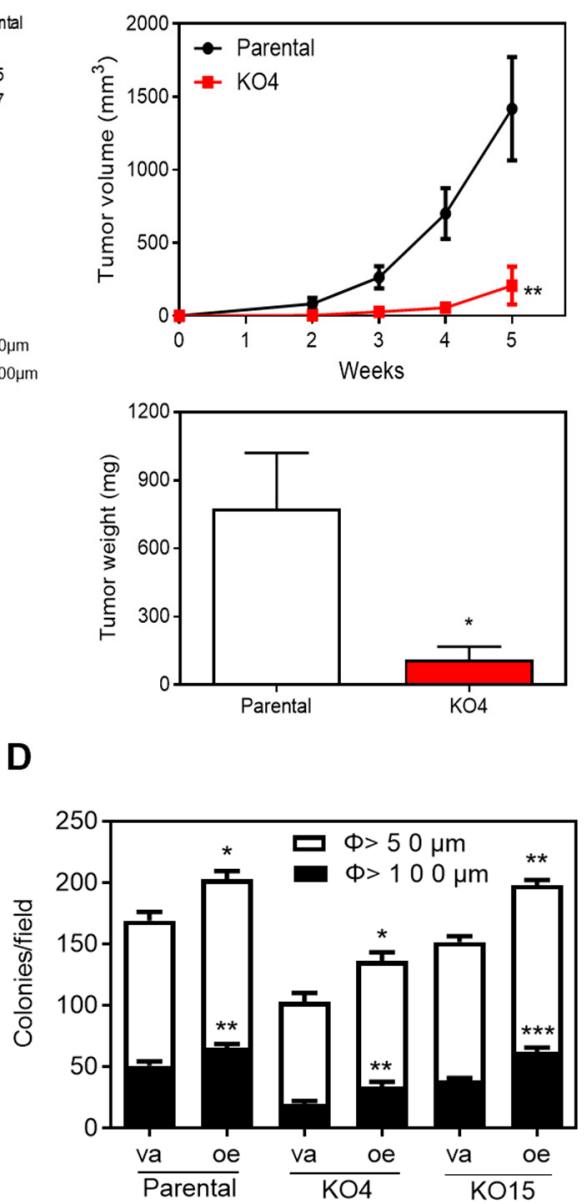

Figure 4. MIR31HG overexpression rescues the suppression brought about by the knockout of MIR31HG in SAS cells. (A) Association between MIR31HG knockout and decreased oncogenicity. Upper Left, the decreased expression of MIR31HG and miR-31 in the knockout cell subclones KO4 and KO15. Upper Right, Lower Left, and Lower Right, the decreased growth, invasion, and colony formation in the knockout cell subclones $\mathrm{KO} 4, \mathrm{KO} 15$, and $\mathrm{KO} 17$ relative to parental cells, respectively. (B) Subcutaneous tumorigenesis assay. Upper, the growth curve of tumors over a 5-week period. Lower, the weight of the resected tumors. (C) Using the KO4 (left panel) and KO15 (right panel) cell subclones, transient MIR31HG overexpression increases the wound closure rate (upper panels) and tumor cell invasion (lower panels). (D) Anchorage-independent colony formation assay. In the parental cells, the KO4 cell subclone and the KO15 cell subclone, transient MIR31HG overexpression increases colony formation. va, vector alone, oe, transient MIR31HG overexpression. ${ }^{*}, p<0.05 ;{ }^{* *}, p<0.01{ }^{* * *}, p<0.001$. 


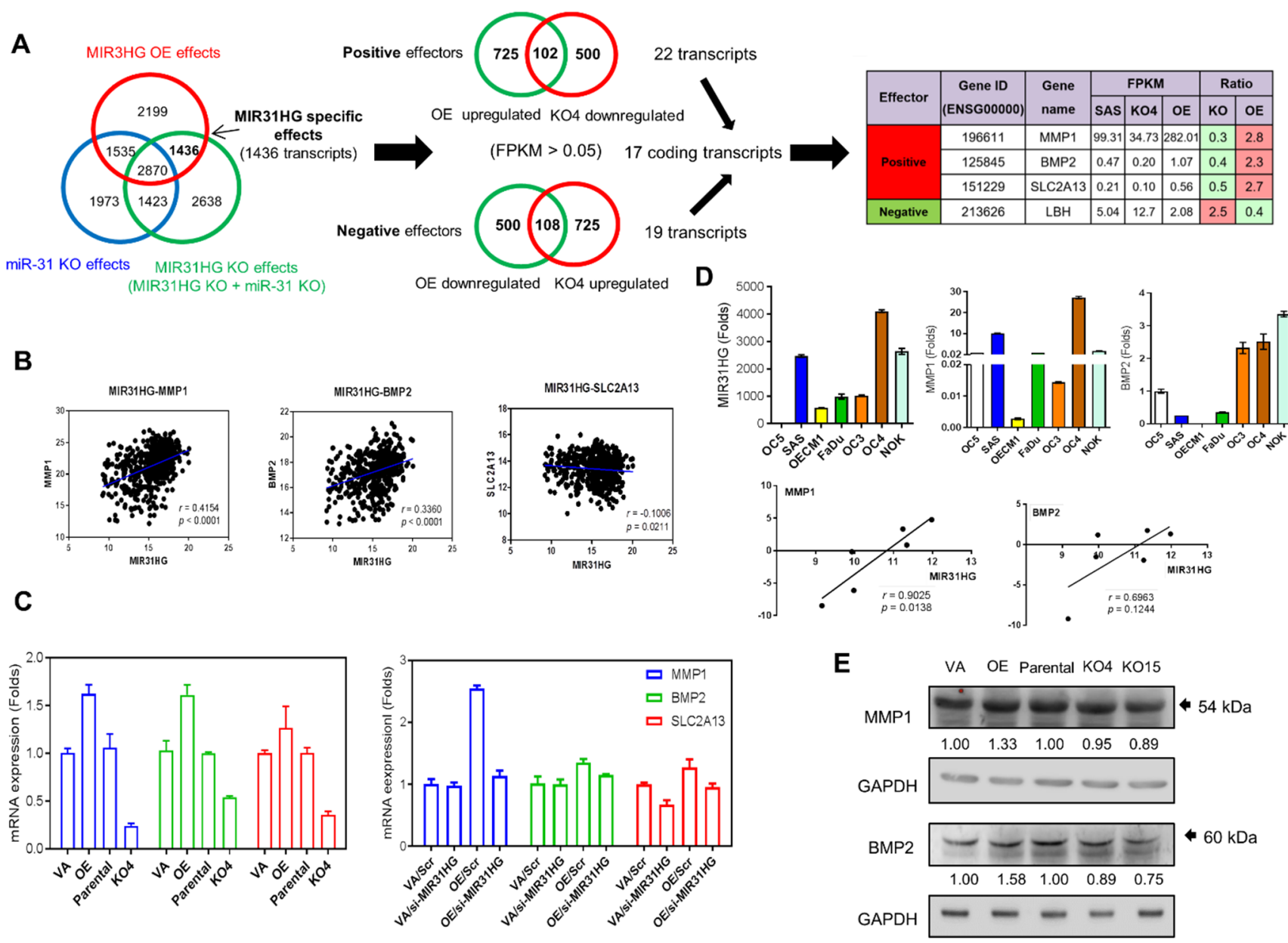

Figure 5. Identification of potential MIR31HG effectors in SAS cells. (A) The strategy using RNASeq data. Left, the identification of MIR31HG specific effectors. Middle, the identification of 22 positive and 19 negative effectors potentially modulated by MIR31HG. Specifically, 17 coding transcripts were potentially modulated by MIR31HG. Right, the expression profile of $M M P 1, B M P 2, S L C 2 A 13$, and LBH, the genes selected for further analysis. (B) The correlation between MIR31HG expression and the expression of MMP1, BMP2, and SCL2A13 in HNSCC tumors of the TCGA dataset. (C) qRT-PCR analysis reveals that the level of MMP1, BMP2 and SCL2A13 mRNA expression in SAS cells with either MIR31HG overexpression or MIR31HG deletion (left), as well as in cells that had been treated with si-MIR31HG or scramble (right). (D) Upper, qRT-PCR analysis to show MIR31HG, MMP1, and BMP2 mRNA expression levels in various OSCC cell lines. Lower, a correlation is found between the expression of MIR31HG and MMP1, but not between MIR31HG and BMP2. (E) Western blot analysis. This shows an increase in MMP1 and BMP2 expression in stable cells with exogenous MIR31HG overexpression, and slightly decreased MMP1 and BMP2 expression in MIR31HG knockout cell subclones. VA or va, vector alone. OE, stable MIR31HG overexpression. oe, transient MIR31HG overexpression. Scr, scramble.

\subsection{LBH Is a Negative Effector of MIR31HG}

In the TCGA HNSCC dataset, a reverse correlation between MIR31HG expression and $L B H$ expression was found (Figure 6A). In OE cells, MIR31HG expression increased, while the $L B H$ mRNA expression decreased. By way of contrast, in the $\mathrm{KO} 4$ cell subclone, $L B H$ mRNA expression increased (Figure 6B, Upper). Furthermore, $L B H$ mRNA expression was also up-regulated in the KO15 and KO17 subclones (Figure 6B, Lower Left). In both the parental SAS cells and OE cells, the knockdown of MIR31HG increased $L B H$ mRNA expression (Figure 6B, Lower Right). Similarly, in the MIR31HG KO cell subclones, $L B H$ protein levels increased to different extents (Figure 6C, Upper). Transient or stable MIR31HG overexpression decreased $L B H$ protein expression, whereas knockdown of MIR31HG expression increased LBH protein expression (Figure 6C, Lower). Western blot analysis further confirmed at $8 \mathrm{~h}$ after transient MIR31HG transfection that there was 
activation of Wnt pathway molecules and up-regulation of MMP1 and BMP2; these changes were accompanied by LBH down-regulation (Figure 6D). A positive correlation between LBH expression and the expression of several Wnt-associated molecules, especially TCF4 and TCF7, could be noted in TCGA HNSCC dataset (Figure S7).

A

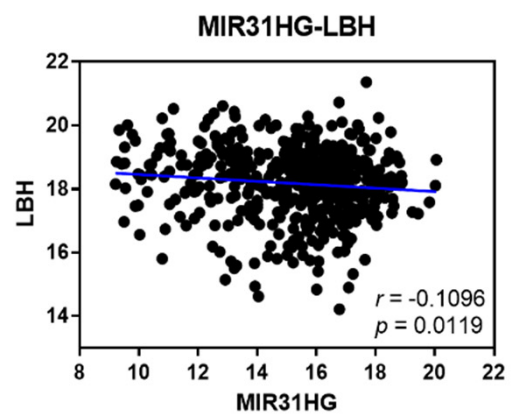

B
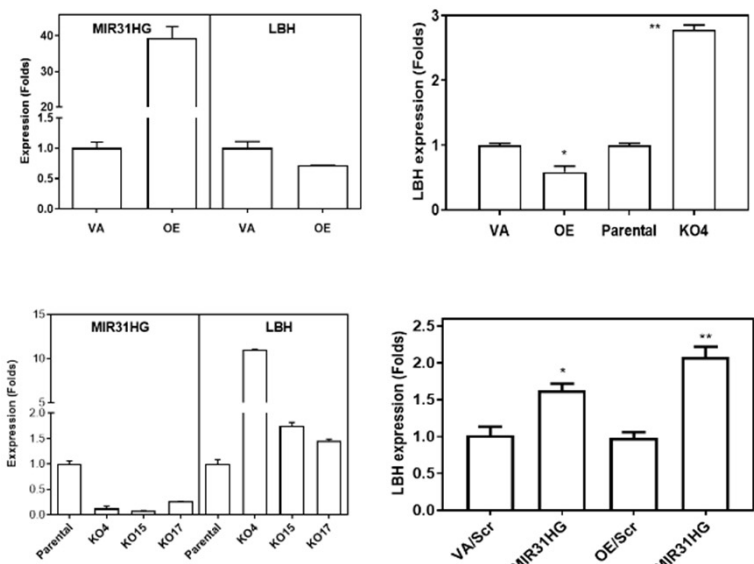

C
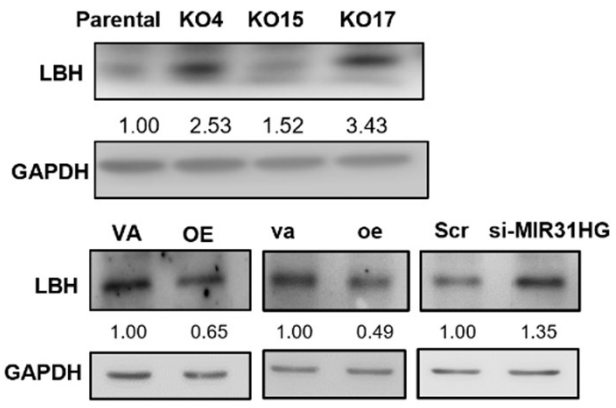

D

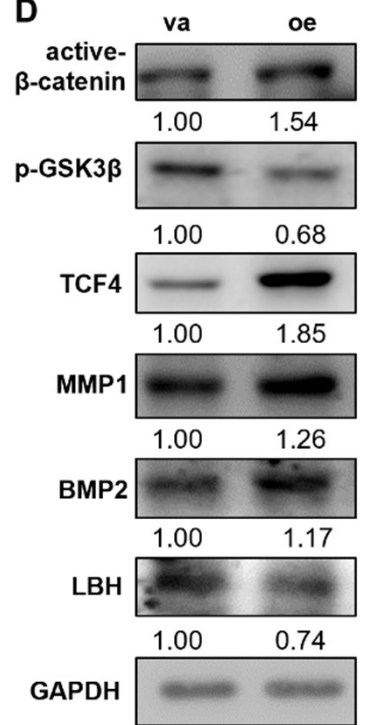

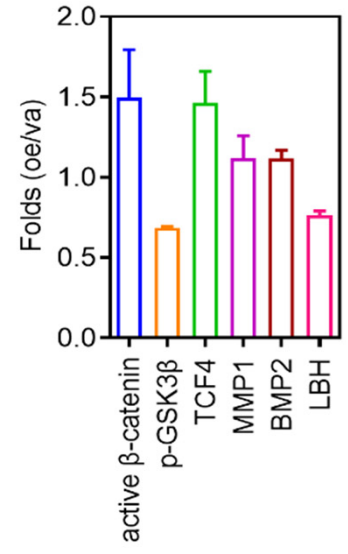

Figure 6. $L B H$ is a negative effector of MIR31HG. (A) A weakly negative correlation between expression of $M I R 31 H G$ and $L B H$ can be seen in HNSCC tumors from the TCGA dataset. (B) qRT-PCR analysis. Upper, decreased LBH expression in MIR31HG overexpression cells, and increased LBH expression in the MIR31HG knockout cell subclone. Lower Left, decreased MIR31HG expression and increased LBH mRNA expression in the MIR31HG knockout cell subclones. Lower Right, knockdown of MIR31HG increases $L B H$ expression in both VA and OE cells. At least duplicate analysis. (C) Western blot analysis. Upper, increased LBH expression in MIR31HG knockout cell subclones. Lower, both stable and transient MIR31HG overexpression decreases LBH protein expression, whereas knockdown of MIR31HG increases LBH protein expression. (D) Western blot analysis. Left, a representative analysis. Transient MIR31HG overexpression activates Wnt signal molecules, increases MMP1 and BMP2 expression, as well as decreasing LBH expression. Right, quantification of duplicate or triplicate analysis. VA or va, vector alone. OE, stable MIR31HG overexpression. oe, transient MIR31HG overexpression. Scr, scramble. ${ }^{*}, p<0.05 ;{ }^{* *}, p<0.01$.

\subsection{The MIR31HG Associated Phenotypes Are Attenuated by LBH}

Transient transfection of the $L B H$ plasmid resulted in a tremendous overexpression of $L B H$ protein in OSCC cells (Figure 7A; Figure S8; Table S2). This caused almost no effect on the proliferation of the OSCC cells (Figure 7B, Upper), but it did reduce the migration and invasion of the OSCC cells (Figure 7B, Lower). In addition, the decreased proliferation, invasion and colony formation capability of the $\mathrm{KO} 4$ cell subclone was reversed by knockdown of $L B H$ (Figure 7C). 
A

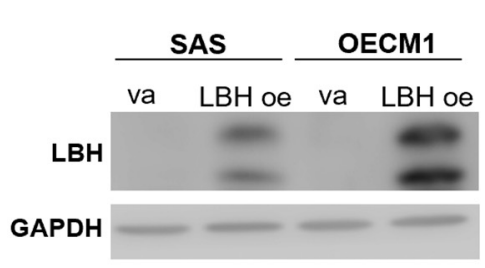

B
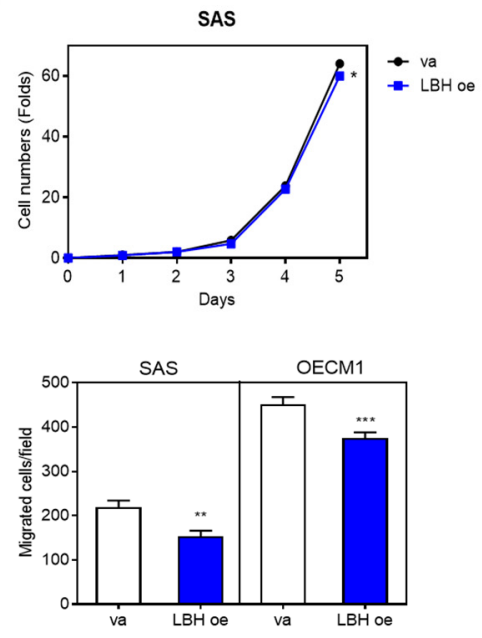

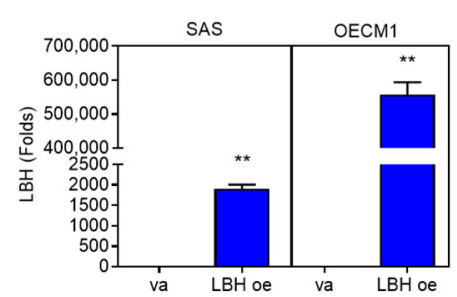

C
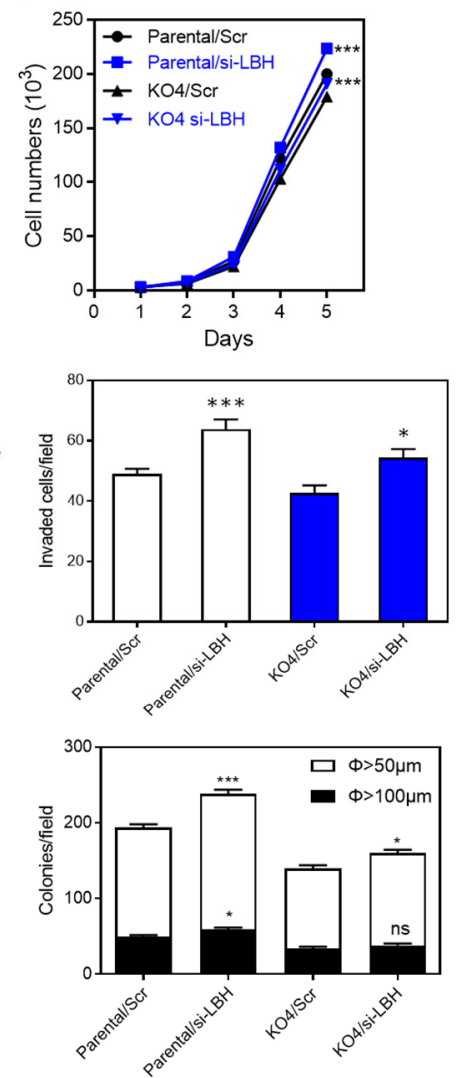

Figure 7. LBH suppresses the migration and invasion of OSCC cells. (A) Transient LBH overexpression in OSCC cells. Left, Western blot analysis. Only very brief exposure was carried out to acquire the images without a burn-through effect, this means that endogenous LBH expression is barely detectable. Right, qRT-PCR analysis shows increased $L B H$ mRNA expression following transient overexpression. (B) Upper, proliferation; Lower Left, migration; Lower Right, invasion. The $L B H$ expression in OSCC cells decreases migration and invasion by OSCC cells, but it does not affect proliferation of OSCC cells. (C) Knockdown of $L B H$ reverts the phenotypes that resulted from MIR31HG deletion. Upper, proliferation; Middle, migration; Lower, anchorage-independent colony formation. va, vector alone; $L B H$ oe, transient $L B H$ overexpression. ${ }^{*}, p<0.05 ; * *, p<0.01 ; * *, p<0.001$.

\section{Discussion}

Both MIR31HG and miR-31 has been found to be up-regulated in HNSCC and in OSCC $[14,19]$. In addition, the up-regulation of $m i R-31$ is known to begin during the OPMD stage [12,13] that precedes the full establishment of OSCC. Sampling of OPMD is somewhat more difficult than OSCC as eradication by means of other than surgical resection remains a therapeutic option $[7,48]$. As a result, this study analyzes brushed samples from OPMD patients. The up-regulation of genes in OPMD samples relative to control samples when identified by this minimally invasive approach suggests that MIR31HG up-regulation occurs early in oral carcinogenesis. Extension of MIR31HG analysis to saliva testing should facilitate the development of non-invasive diagnostic approach for at risk patients [15,49]. To decipher the prognostic implication of MIR31HG up-regulation in OPMD will help to determine the usefulness of $M I R 31 H G$ expression testing when deciding an appropriate interception technique [12].

Studies have shown that both activation of a SP1 response element and the methylation status of the LOC554202 promoter independently may affect MIR31HG expression and miR-31 expression [23,37]. Our previous study has shown that the EGFR/AKT/CEBP $\beta$ cascade activates the LOC554202 promoter bringing about miR-31 up-regulation in OSCC cells [50]. It is likely that this signal axis also underlies the MIR31HG up-regulation in OPMD and OSCC. The present study confirms the potent oncogenic induction is present 
in both stable and transient MIR31HG overexpression systems. To acquire the appropriate reverse insights, we have used a Crispr/Cas9 editing approach to knockout MIR31HG. As there might be various MIR31HG isoforms owing to alternative splicing [51], we designed a double cleavage system to delete the gene completely from the genome. Multiple cell subclones that had undergone deletion of an $\sim 150-\mathrm{Kb}$ genome sequence and these exhibited a consistent reduction in oncogenicity. The deletion of such a long sequence segment by means of Crispr/Cas 9 system was surprising. However, using a similar strategy, deletion of other long spans, up to one hundred Kbs of genomic sequence, have been carried out in other studies [52]. It should be noted that 9p21 is a hotspot locus for gene deletion in HNSCC and many other types of malignancies [20], and it seems likely that the chromosomal structure or molecular apparatus close to MIR31HG may facilitates these gene editing events. As 9p21 is also a gene desert, it has been suggested to be a nodal region for gene interaction [53]; therefore, additional geographic or functional impacts secondary to the structural disruption in this region needs investigation. Since unequivocal oncogenic suppression appears in multiple MIR31HG knockout cell subclones, and this suppression was rescued by MIR31HG overexpression, the cause-effect relationship between MIR31HG and oral carcinogenesis is very strongly supported by our knockout data.

This study has identified a MIR31HG induced differential gene expression profile that is independent of miR-31. MMP1 and BMP2, which are prognostic factors of HNSCC $[5,46,47]$, and are up-regulated by MIR31HG at the transcription level. During the senescence induced by oncogenic stimulation, cytosolic MIR31HG would seem to increase IL1A protein levels, which then transactivates a panel of secretory molecules such as MMP1 [17]. Since concordance between MIR31HG expression and expression of these two secretory molecules has been noted in a HNSCC cohort, and it is known that these secreted molecules seem to be able to modify tumor plasticity via remote effects, this validation of their coordination provides further useful mechanistic insights. Strategies to prevent or abrogate against MIR31HG associated OPMD pathogenesis by targeting of MMP1 or BMP2 need to be considered [54]. The regulatory effects of MIR31HG on other annotated genes linked to oral pathogenesis also requires further investigation.

Many oncogenic signals seem to be activated by MIR31HG in tumor cells $[34,35]$. Our findings identify FAK and Wnt signaling elements as possible key factors related to MIR31HG expression [35]. This study also shows for the first time the inhibitory activity of $L B H$ on invasion and colony formation by OSCC cells. The reversed correlation in expression between MIR31HG and $L B H$ in the various cells and tumor cohorts, along with the reversed phenotypes found between MIR31HG and $L B H$, suggest a cause-effect situation. Although Wnt activation is responsible for $L B H$ up-regulation [39-41], and the TCGA tissue datasets substantiate their positive association, the relevance of the relationship between MIR31HG-Wnt activation and the $L B H$ down-regulation in OSCC remains to be addressed. A direct interaction between MIR31HG and $L B H$ in nucleus, or trans-inactivation of the $L B H$ promoter mediated by TCFs, are two possibilities and require further study. Our findings suggest that activation of FAK contributes to $L B H$ expression, and this issue deserves investigation. As MIR31HG also affects the HIF $1 \alpha$ and represses p21 in HNSCC $[19,36]$, the overall effect seems to be one that brings advantages to OPMD or OSCC progression.

\section{Materials and Methods}

\subsection{Subjects}

Cytobrushed samples from 28 OPMD patients and their matched mucosa were collected at Taipei MacKay Memorial Hospital and National Yang Ming Chiao Tung University Hospital (Table S1). This study was approved by the appropriate ethics reviewing committees with approval numbers 18MMHIS187e and 2019A013, respectively. Libo specimen collection swabs (Iron Will, New Taipei City, Taiwan) were used to collect samples according to a previously used protocol [55]. Written informed consent was obtained from each patient prior to sampling. 


\subsection{Cell Lines}

The OSCC cell lines OC3, OC4, OC5, SAS, OECM1, and FaDu, as well as hTERT immortalized normal oral keratinocytes, designated NOK, were cultured as previously described [2]. Small interference RNA oligonucleotides (Table S5) and their scramble (Scr) control were purchased from Ambion (Austin, TX, USA) or BioTools (New Taipei City, Taiwan). Unless specified, all other reagents were obtained from Sigma-Aldrich (St Louise, MO, USA).

\section{3. qRT-PCR Analysis}

TRI-reagent (Molecular Research Center, Cincinnati, OH) was used to isolate RNA from cells. TaqMan miRNA assay kits (Apply Biosystems, Waltham, MA, USA) were used to quantify the expression of MIR31HG, miR-31, MMP1, BMP2, SLC2A13, and LBH, while GAPDH or RNU6B were used as internal controls (Table S6). $-\triangle \mathrm{Ct}$ is the difference in threshold cycle number between the test gene and the internal control. $-\Delta \Delta \mathrm{Ct}$ is the difference in $-\Delta \mathrm{Ct}$ between the test group and the control group. $2^{-\Delta \Delta \mathrm{Ct}}$ designates the differences in expression across the various groups [1].

\subsection{Western Blotting}

Cell lysates were subjected to Western blot analysis using various primary antibodies (Table S7) and their appropriate secondary antibodies (Table S8). The signals for the tested proteins were normalized against the signal for GAPDH to measure and compare expression [1].

\subsection{Plasmid Construction and Overexpression}

A 2148-bp modified PCR product of the MIR31HG transcript with sticky ends was cloned into the pLV-EF1a-GFP lentiviral vector (Figure S1; Table S2) and the pcDNA 3.1(-) vector (Figure S3; Table S2) to allow stable cell lines to be established by lentiviral infection or transient overexpression by plasmid transfection, respectively [1]. In addition, a 342-bp PCR product amplified from the cDNA of the $L B H$ gene was also cloned into pcDNA 3.1(-) plasmid to allow transient overexpression (Figure S8; Table S2). Transfectin (BioRad, Hercules, CA, USA) was used for all transfections.

4.6. The Implement of Clustered Regularly Interspaced Short Palindromic Repeat (Crispr)/Cas9 Approach for MIR31HG Deletion

The $5^{\prime}$ sgRNA targeting exon 1 and the $3^{\prime}$ sgRNA targeting exon 4 , cloned into the pRGEN_U6_sgRNA vector, was obtained from BioTools. The vectors containing the cloned DNA were then co-transfected with the pRGEN-Cas9-CMV vector into cells to express the two sgRNAs and Cas9, which resulted in the deletion of MIR31HG from the cell genome (Figure S4). After puromycin selection, single cells were selected by limited dilution, and were expanded to become cell subclones. DNA isolated from the cell subclones was subjected to PCR analysis to confirm the deletion of the target locus and the allelic status of the subclone (Figure S4). These PCR products were cloned into a bacteria vector, and plasmid DNAs from randomly selected bacterial colonies were sequenced to confirm that deletion at the MIR31HG locus had occurred [2].

\subsection{Phenotypic and Tumorigenic Assays}

Cell growth, wound closure, anchorage-independent colony formation, drug sensitivity, and transwell migration and transwell invasion assays were carried out according to previously published protocols [1,2]. For the migration and invasion assays, cell growth was arrested by treatment with $1 \mu \mathrm{M}$ hydroxyurea. For the induction of subcutaneous xenografts, $5 \times 10^{5}$ cells were injected into the flanks of nude mice. The resulting tumors had their longest (L) and shortest (S) diameters measured, and their volumes were assessed using the following formula: volume $=0.5 \mathrm{LS}^{2}[1,2]$. This animal study was approved by the Institutional Animal Care and Use Committee of National Yang Ming University. 


\subsection{RNASeq}

After removal of rRNA from total RNA, the remained RNA was fragmented, modified, and subjected to cDNA library construction. Specifically, $9 \mathrm{G} / 150 \mathrm{bp}$ paired end sequencing was performed on an Illumina NovaSeq platform at Wegene Biotech (Taipei, Taiwan). The reads were aligned and the expression was quantified using cufflinks [56].

\subsection{Statistics}

Data are shown as mean \pm SE. Mann-Whitney tests, $t$-tests, two-way ANOVA tests, linear correlation analysis and Kaplan-Meier survival analysis were performed. The tested genes in the HNSCC subset of TCGA database were analyzed using UCSC Xena Functional Genomics Explorer (https: / / xenabrowser.net/, accessed on 18 June 2021). ns, not significant and $1-3$ asterisks $\left({ }^{*},{ }^{* *}\right.$ and $\left.{ }^{* * *}\right)$ represent $p<0.05, p<0.01$ and $p<0.001$, respectively.

\section{Conclusions}

Collectively, this study has identified the up-regulation of MIR31HG at an early stage of oral carcinogenesis. Oncogenic proteins MMP1 and BMP2, together with LBH, which suppresses tumor progression, have been found to act as downstream effectors of MIR31HG. To target MIR31HG is likely to have significant therapeutic efficacy due to the resulting concomitant modulation of multiple downstream effector genes.

Supplementary Materials: The following are available online at https:/ /www.mdpi.com/article/10 $.3390 / \mathrm{ijms} 22168383 / \mathrm{s} 1$.

Author Contributions: Conceptualization, S.-C.L. and K.-W.C.; methodology, W.-W.H. and C.-H.C.; software, H.-F.T.; formal analysis, C.-H.C.; investigation, W.-W.H., S.-R.C. and Y.-C.L.; resources, H.-F.T. and C.-J.L.; writing-original draft preparation, S.-C.L. and K.-W.C.; writing-review and editing, S.-C.L., W.-W.H. and K.-W.C.; funding acquisition, S.-C.L. and K.-W.C. All authors have read and agreed to the published version of the manuscript.

Funding: This study is supported by grants 107-2314-B-010-026-MY3 and 108-2314-B-010-011-MY3 from Ministry of Science and Technology and MOHW110-TDU-B-211-144019 from Ministry of Health and Welfare, Taiwan.

Institutional Review Board Statement: The study was conducted according to the guidelines of the Declaration of Helsinki, and approved by the Institutional Review Board of Taipei MacKay Memorial Hospital and National Yang Ming Chiao Tung University Hospital with approval numbers 18MMHIS187e and 2019A013, respectively.

Informed Consent Statement: Informed consent was obtained from all subjects involved in the study.

Data Availability Statement: Not applicable.

Acknowledgments: We acknowledge the helps provided by Ai-Yuen Hsieh.

Conflicts of Interest: The authors declare no conflict of interest.
Abbreviations
CRISPR Clustered: regularly interspaced, short palindromic repeats
HNSCC Head and neck squamous cell carcinoma
LBH Limb-Bud and Heart development
LncRNA Long non-coding RNA
NSCLC Non-small cell lung cancer
OPMD Oral potentially malignant disorder
OSCC Oral squamous cell carcinoma
TCGA The Cancer Genome Atlas 


\section{References}

1. Liu, C.J.; Tsai, M.M.; Hung, P.S.; Kao, S.Y.; Liu, T.Y.; Wu, K.J.; Chiou, S.H.; Lin, S.C.; Chang, K.W. miR-31 ablates expression of the HIF regulatory factor FIH to activate the HIF pathway in head and neck carcinoma. Cancer Res. 2010, 70, 1635-1644. [CrossRef] [PubMed]

2. Peng, S.Y.; Tu, H.F.; Yang, C.C.; Wu, C.H.; Liu, C.J.; Chang, K.W.; Lin, S.C. miR-134 targets PDCD7 to reduce E-cadherin expression and enhance oral cancer progression. Int. J. Cancer 2018, 143, 2892-2904. [CrossRef] [PubMed]

3. Inchingolo, F.; Santacroce, L.; Ballini, A.; Topi, S.; Dipalma, G.; Haxhirexha, K.; Bottalico, L.; Charitos, I.A. Oral cancer: A historical review. Int. J. Environ. Res. Public Health 2020, 17, 3168. [CrossRef]

4. Sasahira, T.; Kirita, T. Hallmarks of cancer-related newly prognostic factors of oral squamous cell carcinoma. Int. J. Mol. Sci. 2018, 19, 2413. [CrossRef]

5. Siriwardena, S.; Tsunematsu, T.; Qi, G.; Ishimaru, N.; Kudo, Y. Invasion-related factors as potential diagnostic and therapeutic targets in oral squamous cell carcinoma-a review. Int. J. Mol. Sci. 2018, 19, 1462. [CrossRef]

6. Dionne, K.R.; Warnakulasuriya, S.; Zain, R.B.; Cheong, S.C. Potentially malignant disorders of the oral cavity: Current practice and future directions in the clinic and laboratory. Int. J. Cancer 2015, 136, 503-515. [CrossRef]

7. Hanna, R.; Dalvi, S.; Benedicenti, S.; Amaroli, A.; Salagean, T.; Pop, I.D.; Todea, D.; Bordea, I.R. Photobiomodulation therapy in oral mucositis and potentially malignant oral lesions: A therapy towards the future. Cancers 2020, 12, 1949. [CrossRef]

8. Makunin, I.V.; Mattick, J.S. Non-coding RNA. Hum. Mol. Genet. 2006, 15, R17-R29.

9. Kao, Y.Y.; Chou, C.H.; Yeh, L.Y.; Chen, Y.F.; Chang, K.W.; Liu, C.J.; Fan Chiang, C.Y.; Lin, S.C. MicroRNA miR-31 targets SIRT3 to disrupt mitochondrial activity and increase oxidative stress in oral carcinoma. Cancer Lett. 2019, 456, 40-48. [CrossRef] [PubMed]

10. Lu, W.C.; Liu, C.J.; Tu, H.F.; Chung, Y.T.; Yang, C.C.; Kao, S.Y.; Chang, K.W.; Lin, S.C. miR-31 targets ARID1A and enhances the oncogenicity and stemness of head and neck squamous cell carcinoma. Oncotarget 2016, 7, 57254-57267. [CrossRef] [PubMed]

11. Tseng, S.H.; Yang, C.C.; Yu, E.H.; Chang, C.; Lee, Y.S.; Liu, C.J.; Chang, K.W.; Lin, S.C. K14-EGFP-miR-31 transgenic mice have high susceptibility to chemical-induced squamous cell tumorigenesis that is associating with Ku80 repression. Int. J. Cancer 2015, 136, 1263-1275. [CrossRef] [PubMed]

12. Hung, K.F.; Liu, C.J.; Chiu, P.C.; Lin, J.S.; Chang, K.W.; Shih, W.Y.; Kao, S.Y.; Tu, H.F. MicroRNA-31 upregulation predicts increased risk of progression of oral potentially malignant disorder. Oral Oncol. 2016, 53, 42-47. [CrossRef]

13. Hung, P.S.; Tu, H.F.; Kao, S.Y.; Yang, C.C.; Liu, C.J.; Huang, T.Y.; Chang, K.W.; Lin, S.C. miR-31 is upregulated in oral premalignant epithelium and contributes to the immortalization of normal oral keratinocytes. Carcinogenesis 2014, 35, 1162-1171. [CrossRef]

14. Liu, C.J.; Kao, S.Y.; Tu, H.F.; Tsai, M.M.; Chang, K.W.; Lin, S.C. Increase of microRNA miR-31 level in plasma could be a potential marker of oral cancer. Oral Dis. 2010, 16, 360-364. [CrossRef]

15. Liu, C.J.; Lin, S.C.; Yang, C.C.; Cheng, H.W.; Chang, K.W. Exploiting salivary miR-31 as a clinical biomarker of oral squamous cell carcinoma. Head Neck 2012, 34, 219-224. [CrossRef] [PubMed]

16. Gupta, R.A.; Shah, N.; Wang, K.C.; Kim, J.; Horlings, H.M.; Wong, D.J.; Tsai, M.C.; Hung, T.; Argani, P.; Rinn, J.L.; et al. Long non-coding RNA HOTAIR reprograms chromatin state to promote cancer metastasis. Nature 2010, 464, 1071-1076. [CrossRef]

17. Montes, M.; Lubas, M.; Arendrup, F.S.; Mentz, B.; Rohatgi, N.; Tumas, S.; Harder, L.M.; Skanderup, A.J.; Andersen, J.S.; Lund, A.H. The long non-coding RNA MIR31HG regulates the senescence associated secretory phenotype. Nat. Commun. 2021, $12,2459$. [CrossRef] [PubMed]

18. Montes, M.; Nielsen, M.M.; Maglieri, G.; Jacobsen, A.; Hojfeldt, J.; Agrawal-Singh, S.; Hansen, K.; Helin, K.; van de Werken, H.J.G.; Pedersen, J.S.; et al. The lncRNA MIR31HG regulates p16(INK4A) expression to modulate senescence. Nat. Commun. 2015, 6, 6967. [CrossRef] [PubMed]

19. Shih, J.W.; Chiang, W.F.; Wu, A.T.H.; Wu, M.H.; Wang, L.Y.; Yu, Y.L.; Hung, Y.W.; Wang, W.C.; Chu, C.Y.; Hung, C.L.; et al. Long noncoding RNA LncHIFCAR/MIR31HG is a HIF-1alpha co-activator driving oral cancer progression. Nat. Commun. 2017, 8, 15874. [CrossRef] [PubMed]

20. Rybicki, B.A.; Savera, A.T.; Gomez, J.A.; Patel, S.C.; Ballard, N.E.; Benninger, M.S.; Zarbo, R.J.; Van Dyke, D.L. Allelic loss and tumor pathology in head and neck squamous cell carcinoma. Mod. Pathol. 2003, 16, 970-979. [CrossRef] [PubMed]

21. Cai, P.; Li, H.; Huo, W.; Zhu, H.; Xu, C.; Zang, R.; Lv, W.; Xia, Y.; Tang, W. Aberrant expression of LncRNA-MIR31HG regulates cell migration and proliferation by affecting miR-31 and miR-31* in Hirschsprung's disease. J. Cell Biochem. 2018, 119, 8195-8203. [CrossRef] [PubMed]

22. Chu, J.; Jia, J.; Yang, L.; Qu, Y.; Yin, H.; Wan, J.; He, F. LncRNA MIR31HG functions as a ceRNA to regulate c-Met function by sponging miR-34a in esophageal squamous cell carcinoma. Biomed. Pharm. 2020, 128, 110313. [CrossRef] [PubMed]

23. Dandan, W.; Jianliang, C.; Haiyan, H.; Hang, M.; Xuedong, L. Long noncoding RNA MIR31HG is activated by SP1 and promotes cell migration and invasion by sponging miR-214 in NSCLC. Gene 2019, 692, 223-230. [CrossRef] [PubMed]

24. Eide, P.W.; Eilertsen, I.A.; Sveen, A.; Lothe, R.A. Long noncoding RNA MIR31HG is a bona fide prognostic marker with colorectal cancer cell-intrinsic properties. Int. J. Cancer 2019, 144, 2843-2853. [CrossRef]

25. He, A.; Chen, Z.; Mei, H.; Liu, Y. Decreased expression of LncRNA MIR31HG in human bladder cancer. Cancer Biomark. 2016, 17, 231-236. [CrossRef]

26. Li, Y. MIR31HG exhibits oncogenic property and acts as a sponge for miR-361-3p in cervical carcinoma. Biochem. Biophys Res. Commun. 2020, 529, 890-897. [CrossRef] 
27. Lin, Y.; Zhang, C.S.; Li, S.J.; Li, Z.; Sun, F.B. LncRNA LOC554202 promotes proliferation and migration of gastric cancer cells through regulating p21 and E-cadherin. Eur. Rev. Med. Pharm. Sci. 2018, 22, 8690-8697.

28. Nie, F.Q.; Ma, S.; Xie, M.; Liu, Y.W.; De, W.; Liu, X.H. Decreased long noncoding RNA MIR31HG is correlated with poor prognosis and contributes to cell proliferation in gastric cancer. Tumour. Biol. 2016, 37, 7693-7701. [CrossRef]

29. Qin, J.; Ning, H.; Zhou, Y.; Hu, Y.; Yang, L.; Huang, R. LncRNA MIR31HG overexpression serves as poor prognostic biomarker and promotes cells proliferation in lung adenocarcinoma. Biomed. Pharm. 2018, 99, 363-368. [CrossRef]

30. Rajbhandari, R.; McFarland, B.C.; Patel, A.; Gerigk, M.; Gray, G.K.; Fehling, S.C.; Bredel, M.; Berbari, N.F.; Kim, H.; Marks, M.P.; et al. Loss of tumor suppressive microRNA-31 enhances TRADD/NF-kappaB signaling in glioblastoma. Oncotarget 2015, 6, 17805-17816. [CrossRef] [PubMed]

31. Sun, K.; Zhao, X.; Wan, J.; Yang, L.; Chu, J.; Dong, S.; Yin, H.; Ming, L.; He, F. The diagnostic value of long non-coding RNA MIR31HG and its role in esophageal squamous cell carcinoma. Life Sci. 2018, 202, 124-130. [CrossRef] [PubMed]

32. Yan, S.; Tang, Z.; Chen, K.; Liu, Y.; Yu, G.; Chen, Q.; Dang, H.; Chen, F.; Ling, J.; Zhu, L.; et al. Long noncoding RNA MIR31HG inhibits hepatocellular carcinoma proliferation and metastasis by sponging microRNA-575 to modulate ST7L expression. J. Exp. Clin. Cancer Res. 2018, 37, 214. [CrossRef] [PubMed]

33. Yang, H.; Liu, P.; Zhang, J.; Peng, X.; Lu, Z.; Yu, S.; Meng, Y.; Tong, W.M.; Chen, J. Long noncoding RNA MIR31HG exhibits oncogenic property in pancreatic ductal adenocarcinoma and is negatively regulated by miR-193b. Oncogene 2015, $35,3647$. [CrossRef] [PubMed]

34. Wang, B.; Jiang, H.; Wang, L.; Chen, X.; Wu, K.; Zhang, S.; Ma, S.; Xia, B. Increased MIR31HG lncRNA expression increases gefitinib resistance in non-small cell lung cancer cell lines through the EGFR/PI3K/AKT signaling pathway. Oncol. Lett. 2017, 13, 3494-3500. [CrossRef]

35. Zheng, S.; Zhang, X.; Wang, X.; Li, J. MIR31HG promotes cell proliferation and invasion by activating the Wnt/ $\beta$-catenin signaling pathway in non-small cell lung cancer. Oncol. Lett. 2019, 17, 221-229. [CrossRef]

36. Wang, R.; Ma, Z.; Feng, L.; Yang, Y.; Tan, C.; Shi, Q.; Lian, M.; He, S.; Ma, H.; Fang, J. LncRNA MIR31HG targets HIF1A and P21 to facilitate head and neck cancer cell proliferation and tumorigenesis by promoting cell-cycle progression. Mol. Cancer 2018, 17, 162. [CrossRef]

37. Augoff, K.; McCue, B.; Plow, E.F.; Sossey-Alaoui, K. miR-31 and its host gene lncRNA LOC554202 are regulated by promoter hypermethylation in triple-negative breast cancer. Mol. Cancer 2012, 11, 5. [CrossRef] [PubMed]

38. Briegel, K.J.; Joyner, A.L. Identification and characterization of Lbh, a novel conserved nuclear protein expressed during early limb and heart development. Dev. Biol. 2001, 233, 291-304. [CrossRef] [PubMed]

39. Lindley, L.E.; Curtis, K.M.; Sanchez-Mejias, A.; Rieger, M.E.; Robbins, D.J.; Briegel, K.J. The WNT-controlled transcriptional regulator LBH is required for mammary stem cell expansion and maintenance of the basal lineage. Development 2015, 142, 893-904. [CrossRef]

40. Rieger, M.E.; Sims, A.H.; Coats, E.R.; Clarke, R.B.; Briegel, K.J. The embryonic transcription cofactor LBH is a direct target of the Wnt signaling pathway in epithelial development and in aggressive basal subtype breast cancers. Mol. Cell Biol 2010, 30, 4267-4279. [CrossRef] [PubMed]

41. Ashad-Bishop, K.; Garikapati, K.; Lindley, L.E.; Jorda, M.; Briegel, K.J. Loss of Limb-Bud-and-Heart (LBH) attenuates mammary hyperplasia and tumor development in MMTV-Wnt1 transgenic mice. Biochem. Biophys. Res. Commun. 2019, 508, 536-542. [CrossRef]

42. Deng, M.; Yu, R.; Wang, S.; Zhang, Y.; Li, Z.; Song, H.; Liu, B.; Xu, L.; Wang, X.; Zhang, Z.; et al. Limb-Bud and Heart attenuates growth and invasion of human lung adenocarcinoma cells and predicts survival outcome. Cell Physiol. Biochem. 2018, 47, 223-234. [CrossRef]

43. Liu, Q.; Guan, X.; Lv, J.; Li, X.; Wang, Y.; Li, L. Limb-bud and Heart (LBH) functions as a tumor suppressor of nasopharyngeal carcinoma by inducing G1/S cell cycle arrest. Sci. Rep. 2015, 5, 7626. [CrossRef]

44. Liu, Q.; Li, E.; Huang, L.; Cheng, M.; Li, L. Limb-bud and Heart overexpression inhibits the proliferation and migration of PC3M cells. J. Cancer 2018, 9, 424-432. [CrossRef] [PubMed]

45. Wu, A.; Zhang, L.; Luo, N.; Zhang, L.; Li, L.; Liu, Q. Limb-bud and heart (LBH) inhibits cellular migration, invasion and epithelial-mesenchymal transition in nasopharyngeal carcinoma via downregulating alphaB-crystallin expression. Cell Signal. 2021, 85, 110045. [CrossRef] [PubMed]

46. Reis, P.P.; Tokar, T.; Goswami, R.S.; Xuan, Y.; Sukhai, M.; Seneda, A.L.; Moz, L.E.S.; Perez-Ordonez, B.; Simpson, C.; Goldstein, D.; et al. A 4-gene signature from histologically normal surgical margins predicts local recurrence in patients with oral carcinoma: Clinical validation. Sci. Rep. 2020, 10, 1713. [CrossRef] [PubMed]

47. Sand, J.P.; Kokorina, N.A.; Zakharkin, S.O.; Lewis, J.S., Jr.; Nussenbaum, B. BMP-2 expression correlates with local failure in head and neck squamous cell carcinoma. Otolaryngol. Head Neck Surg. 2014, 150, 245-250. [CrossRef]

48. Cloitre, A.; Rosa, R.W.; Arrive, E.; Fricain, J.C. Outcome of CO2 laser vaporization for oral potentially malignant disorders treatment. Med. Oral Patol. Oral Cir. Bucal. 2018, 23, e237-e247. [CrossRef]

49. Tang, H.; Wu, Z.; Zhang, J.; Su, B. Salivary lncRNA as a potential marker for oral squamous cell carcinoma diagnosis. Mol. Med. Rep. 2013, 7, 761-766. [CrossRef] [PubMed]

50. Lu, W.C.; Kao, S.Y.; Yang, C.C.; Tu, H.F.; Wu, C.H.; Chang, K.W.; Lin, S.C. EGF up-regulates miR-31 through the C/EBPbeta signal cascade in oral carcinoma. PLoS ONE 2014, 9, e108049. 
51. Wu, S.; Nitschke, K.; Worst, T.S.; Fierek, A.; Weis, C.A.; Eckstein, M.; Porubsky, S.; Kriegmair, M.; Erben, P. Long noncoding RNA MIR31HG and its splice variants regulate proliferation and migration: Prognostic implications for muscle invasive bladder cancer. J. Exp. Clin. Cancer Res. 2020, 39, 288. [CrossRef]

52. Wang, Q.; Gong, Y.; He, Y.; Xin, Y.; Lv, N.; Du, X.; Li, Y.; Jeong, B.R.; Xu, J. Genome engineering of Nannochloropsis with hundred-kilobase fragment deletions by Cas9 cleavages. Plant J. 2021, 106, 1148-1162. [CrossRef] [PubMed]

53. Harismendy, O.; Notani, D.; Song, X.; Rahim, N.G.; Tanasa, B.; Heintzman, N.; Ren, B.; Fu, X.D.; Topol, E.J.; Rosenfeld, M.G.; et al. 9p21 DNA variants associated with coronary artery disease impair interferon-gamma signalling response. Nature 2011, 470, 264-268. [CrossRef]

54. Khattab, H.M.; Kubota, S.; Takigawa, M.; Kuboki, T.; Sebald, W. The BMP-2 mutant L51P: A BMP receptor IA binding-deficient inhibitor of noggin. J. Bone Min. Metab. 2019, 37, 199-205. [CrossRef] [PubMed]

55. Lin, S.C.; Liu, C.J.; Ko, S.Y.; Chang, H.C.; Liu, T.Y.; Chang, K.W. Copy number amplification of 3q26-27 oncogenes in microdissected oral squamous cell carcinoma and oral brushed samples from areca chewers. J. Pathol. 2005, 206, 417-422. [CrossRef]

56. Trapnell, C.; Roberts, A.; Goff, L.; Pertea, G.; Kim, D.; Kelley, D.R.; Pimentel, H.; Salzberg, S.L.; Rinn, J.L.; Pachter, L. Differential gene and transcript expression analysis of RNA-seq experiments with TopHat and Cufflinks. Nat. Protoc. 2012, 7, 562-578. [CrossRef] [PubMed] 